\title{
Experimental Study on the Cable Tension Based on Non-Contact Dynamic Deflection Equipment
}

\author{
Zhenhua Dong ${ }^{1,2, *}$, Jinquan Zhang ${ }^{1,2}$, Pengfei Li ${ }^{1,2}$, Yan Mao ${ }^{1,2}$ \\ ${ }^{1}$ Research Institute of Highway Science of Transport Ministry, Beijing, China \\ ${ }^{2}$ Key Laboratory of Old Bridge Inspection and Reinforcement Technology Industry, Beijing, China \\ Email address: \\ dongzhenhua2009@126.com (Zhenhua Dong), rioh_jqzhang@163.com (Jinquan Zhang), pf.li@rioh.cn (Pengfei Li), \\ y.mao@rioh.cn (Yan Mao) \\ ${ }^{*}$ Corresponding author
}

\section{To cite this article:}

Zhenhua Dong, Jinquan Zhang, Pengfei Li, Yan Mao. Experimental Study on the Cable Tension Based on Non-Contact Dynamic Deflection Equipment. American Journal of Mechanics and Applications. Vol. 8, No. 2, 2020, pp. 25-32. doi: 10.11648/j.ajma.20200802.11

Received: August 25, 2020; Accepted: October 12, 2020; Published: October 17, 2020

\begin{abstract}
For the contact and wired measurement technology of cable tension, the factors of complicated bridge site conditions, data acquisition and transmission, wave data processing and sensor contact should be considered in practical application, which affect seriously the measure result accuracy, work efficiency and the measure feasibility. In order to improve the limitation of the existing cable tension measurement technology, the feasibility and key factors of non-contact dynamic deflection measurement technology is studied. A cable specimen with length of $12 \mathrm{~m}$ was designed and made, and the steel strand is used in it, and the non-contact vibration testing device is used. The frequency and tension of the cable and the strain of steel strands are analyzed, and the results show that the effect of measure target position on the fundamental frequency of the cable is obviously little, and the tension of the subsequent steel strand can decrease the tension strain of the stretched steel strand, that is, the tension of the stretched steel strand is reduced. Furthermore, the maximum difference between calculated and measured tension of the cable is about $17.7 \%$ during loading stage. When the unloaded cable tension is less than $20.6 \%$, the difference between calculated and measured tension is less than $10.0 \%$. It can be seen that the tension and tension loss of the cable can be accurately estimated by using the non-contact dynamic deflection technology, and it can improve the work efficiency and the measure feasibility due to the less measure targets and larger data transmission distance.
\end{abstract}

Keywords: Cable, Tension, Dynamic Test, Non-contact Dynamic Deflection Test, Fundamental Frequency

\section{Introduction}

In view of the restrictions of hydrology situation, geological and environmental conditions, the strict requirements on span of bridge, the structure weight, material performance and mechanical performance of structure system are proposed, and then the long-span bridge of Suspension Cable Bridge, Cable-Stayed Bridge and Derrick Bridge are widely applied. The significant characteristics of the large bridge with cables are the higher crossing ability, less material consuming, excellent structural style et al. The cable is as the key component of the long-span Bridge of suspension Cable Bridge, Cable-Stayed Bridge and Derrick Bridge. Under the coupling effect of wind load, rain load, temperature effect, vehicle load, vibrate load et al, the tension force and deformation of the cable are cyclic alternating changed, and then the fatigue cracking on steel casing at the end of cable and damage on the surface antiseptic layer of the cable body are caused. Under the influence of humidity, temperature and water, the cable corrosion is present quickly, which can shorten the service durability life of the cable. Therefore, the cable can be the key fragile component to affect the structural safety and integrity under long-term high stress. With the increase of long-term cumulative damage, it can urge the cable tension to a critical state that is not suitable to use, and then the cable may fail under the conventional load; in addition, the cumulative damage causes the resistance attenuation of the -cable, which will affect the cable safety, even the safety of the whole structure system. In 
order to effectively detect and monitor the force change and damage situation of the cable, the researchers have carried out the cable stress monitor [1-3] and damage detection by acoustic emission [4-7] and electromagnetic technology [8-10]. Furthermore, the testing methods of pressure meter, the pressure sensor and the vibration are commonly applied to obtain the cable tension at present. The test principle, applicability and technical characteristics of the above test methods are stated in literatures [11-12], in which the vibration method has become the main test means of cable tension because of its low cost and convenience.

For the cable force vibration test method, the acceleration sensor is usually placed on the surface of the cable body, and the artificial or environmental excitation method is adopted to obtain the multi-order frequency of the cable. Based on the string theory, the cable force is calculated. In practical application of vibration test method, the higher requirements on the installation position of acceleration sensor, environmental interference ability, filtering ability on vibration waveform and spectrum processing technology are proposed. In addition, partial differential equations of free vibration of cable body under different boundary conditions is established, and then the analytic method is adopted to establish the computational relationship between cable force and frequency [13-14]. The researchers pointed out that the sensitive parameters affecting the calculation cable tension accuracy were the bending stiffness, slope, boundary conditions and additional mass of the cable, and established the explicit analysis method of the cable force. However, for the short cable, the influence of the boundary conditions on the cable tension is great. Therefore, the factors of cable length, constraint situations and additional mass should be considered to calculate the cable force.

Compared with the traditional contact testing method of cable force, the proposed non-contact testing method has some advantages in the aspects of measure point stability, data transmission, testing efficiency and accuracy. The non-contact dynamic deflection measurement technology adopts digital image technology to analyze the two images before and after the cable deformation, and then it is to measure the two-dimensional surface deformation. It can realize the full-scale measurement of the structure, and has the advantages of high precision, convenience, small equipment loss, small input, and low requirements for equipment and measuring environment. This method can be used to directly measure the surface displacement and deformation field for the various scales object under the load action. In this paper, the research on the parameters and accuracy of non-contact test technology is carried out. Furthermore, the specific implementation points, test accuracy and application range of the non-contact dynamic deflection measurement technology are put forward. The research results can provide some data and theoretical support for the further improvement and practical application of the cable force test methods of the non-contact dynamic deflection measurement technology.

\section{Theoretical Basis of the Non-contact Dynamic Deflection Measurement Technology}

The implementation steps for non-contact dynamic deflection measurement method are as follows. That is to obtain the structural deformation image saved in memory module, image displacement, object face displacement, displacement-time curve in turn. Among them, the target position is firstly set, and the reference sub-region image surrounded on the target center is defined, it is searched by the relevant function, and then the actual displacement of the target is determined according to the ratio of the image displacement to the object displacement. The non-contact dynamic testing technology is used to capture the target displacement on the cable. The measured displacement-time curve is transformed to frequency spectrum curves by Fourier transform function, and then the basis frequency of the cable is obtained, and it is used to calculate the cable force by the function with frequency and cable force.

When the cable vibrates perpendicular to the axis, the displacement expression at any point is as follows:

$$
\mu=\mu(x, t)
$$

Where $\mu$ is the displacement at any section; $x$ is the section position along the cable length direction; $t$ denotes the time.

For microelement beam with length of $d x$, the equilibrium differential equation is established, and then the free vibration equation of the cable is deduced as:

$$
E I \frac{\partial^{4} \mu}{\partial x^{4}}-T \frac{\partial^{2} \mu}{\partial x^{2}}+m \frac{\partial^{2} \mu}{\partial t^{2}}=0
$$

Where $E I$ is the section bending stiffness of the cable; $m$ is the per unit length mass of the cable; $T$ is the tension force of the cable.

When the boundary conditions at both ends of the cable are hinge, according to the formula (2), the cable force can be calculated as shown in Equation (3).

$$
T=\frac{4 m L^{2} f_{n}^{2}}{n^{2}}-\frac{n^{2} E I \pi^{2}}{L^{2}}
$$

In which $f_{n}$ is the $\mathrm{n}^{\text {th }}$ frequency of the cable; $n$ is the vibration order; $\mathrm{L}$ is the length of the cable.

For the cable of the length more than $10 \mathrm{~m}$, the influence of $E I$ on cable force can be ignored. Then the calculation formula of cable tension is as

$$
T=\frac{4 m L^{2} f_{n}^{2}}{n^{2}}
$$

For a particular cable, its unit mass $m$ and length $L$ are known. Assuming that the flexural stiffness EI is constant value, the formula (3) can be translated as 


$$
T=K_{1}\left(\frac{f_{n}}{n}\right)^{2}+n^{2} K_{2}
$$

Where $K_{1}, K_{2}$ is constant respectively, it can be measured by the pressure sensor or the jack or vibration method during the construction period of the cable. When $n$ is equal to 1 , the formula (5) can be translated as

$$
T=K_{1} f_{1}^{2}+n^{2} K_{2}
$$

Assuming that the cable force is of $T_{1}$, and the corresponding first-order fundamental frequency is $f_{11}$; the cable tension of $T_{2}$ is correspond to fundamental frequency of $f_{21}$, and the calculation formulas of $K_{1}$ and $K_{2}$ are as follows:

$$
\begin{aligned}
& K_{1}=\frac{T_{2}-T_{1}}{f_{21}^{2}-f_{11}^{2}} \\
& K_{2}=\frac{T_{1} f_{21}^{2}-T_{2} f_{11}^{2}}{f_{21}^{2}-f_{11}^{2}}
\end{aligned}
$$

Therefore, the cable force can be measured accurately according to the corresponding fundamental frequency.

\section{Test plan}

\subsection{Geometric Configuration of the Cable Specimen}

The pre-stressed steel strand of high strength and low relaxation is used in the stay cable, and its standard strength should be more than $1860 \mathrm{MPa}$, and it should be satisfied with the performance requirements in the current "Pre-stressed Concrete Steel strand "guide. The test cable specimen adopts $1 \times 7$ (seven-strand) steel strand with equivalent diameter of $15.2 \mathrm{~mm}$. The diameter of the cable specimen made by $(8+1)$ twisting rule is $50.4 \mathrm{~mm}$. The total length of the component is $15 \mathrm{~m}$, and the effective length is $12 \mathrm{~m}$. The transverse section diagram of the test cable specimen is shown in Figure 1(a), and the longitudinal arrangement diagram is shown in Figure 1(b).

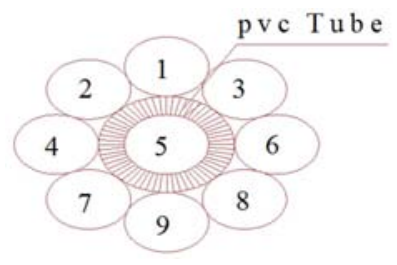

(a) Cross section

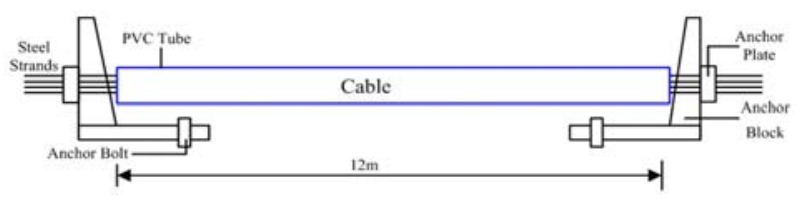

(b) Longitudinal arrangement

Figure 1. Geometric configuration of the test cable specimen.

\subsection{Loading and Measurement Plan}

The each steel strand in the cable specimen is stretched step by step to target tension force, and the dynamic deflection of the target point along the cable length and fundamental frequency of the cable are measured at each loading step. The target position and vibration testing program are shown in Figure 2. Considering the factors of tensile force, number of tensioned steel strands, loading and unloading case, the test parameters were set as shown in Table 1. Each steel strand is stretched to a full tensile force of $6 \mathrm{t}$ by $2 \sim 3$ steps loading. When unloading, each steel strand is directly unloaded to zero.

\begin{tabular}{|c|c|c|c|c|c|c|}
\hline \multirow{2}{*}{\multicolumn{2}{|c|}{ Case Number }} & \multicolumn{3}{|c|}{ Tension step by step } & \multirow{2}{*}{ (4) } & \multirow{2}{*}{ (5) } \\
\hline & & (1) & (2) & (3) & & \\
\hline $\mathrm{J} 1$ & & $1 / 2$ & $1 / 4$ & -- & 1 & 1 \\
\hline $\mathrm{J} 2$ & & $2 / 6$ & $2 / 8$ & -- & 2 & 2 \\
\hline $\mathrm{J} 3$ & & $3 / 10$ & $3 / 12$ & $3 / 14$ & 3 & 3 \\
\hline $\mathrm{J} 4$ & & $4 / 16$ & $4 / 18$ & $4 / 20$ & 4 & 4 \\
\hline J5 & loading & $5 / 22$ & $5 / 24$ & $5 / 26$ & 5 & 5 \\
\hline J6 & & $6 / 28$ & $4 / 30$ & $4 / 32$ & 6 & 6 \\
\hline $\mathrm{J} 7$ & & $7 / 34$ & $7 / 36$ & $7 / 38$ & 7 & 7 \\
\hline J8 & & $8 / 40$ & $8 / 42$ & $8 / 44$ & 8 & 8 \\
\hline J9 & & $9 / 46$ & $9 / 48$ & $9 / 50$ & 9 & 9 \\
\hline $\mathrm{X} 1$ & & $1 / 0$ & & $8 / 44$ & 8 & 9 \\
\hline $\mathrm{X} 2$ & & $2 / 0$ & & $7 / 38$ & 7 & 8 \\
\hline $\mathrm{X} 3$ & & $3 / 0$ & & $6 / 32$ & 6 & 7 \\
\hline $\mathrm{X} 4$ & & $4 / 0$ & & $5 / 26$ & 5 & 6 \\
\hline X5 & unloading & $5 / 0$ & & $4 / 20$ & 4 & 5 \\
\hline X6 & & $6 / 0$ & & $3 / 14$ & 3 & 4 \\
\hline $\mathrm{X} 7$ & & $7 / 0$ & & $2 / 8$ & 2 & 3 \\
\hline $\mathrm{X} 8$ & & $8 / 0$ & & $1 / 4$ & 1 & 2 \\
\hline X9 & & $9 / 0$ & & $0 / 0$ & 0 & 1 \\
\hline
\end{tabular}
The designed full tension value of the cable specimen ( 9 steel strands) is $54 \mathrm{t}$.

Table 1. Testing cases arrangement.

Note: The designed full tension of each steel strands is $4 \mathrm{t}$ or $6 \mathrm{t}$ respectively; It is loaded to $2 \mathrm{t}-4 \mathrm{t}-6 \mathrm{t}$ step by step.

(1) The number of tensioned strands /the total tension force ( $t)$.

(2) The number of tensioned strands /the total tension force $(t)$.

(3) The number of tensioned strands /the total tension force $(t)$.

(4) The number of steel strands with designed full tension force (roots).

(5) The serial number of loaded and unloaded steel strands.

Six target points were posted along the length of the cable, and they are as shown in Figure 2(a). After loading and unloading on one steel strand step by step, the artificially stimulation is used to the test cable. The dynamic displacement time-history curves of different targets is measured respectively. Further, the dynamic characteristic parameters of the cable were obtained by Fourier Transformation.

In this test, loading and unloading tensile forces are controlled by staff, so the differences between the actual tensile forces and the design values can be presented. In order to measure the actual tension of the test cable, a pressure sensor is installed on the end of each steel strand. The measurement range of the pressure sensor is 30t. In addition, two strain gauges are arranged near the middle of each steel strand, and it is used to measure the tension strain of the steel strand during loading and unloading. 


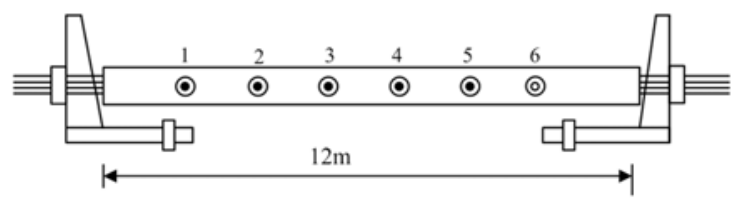

(a) Target points position

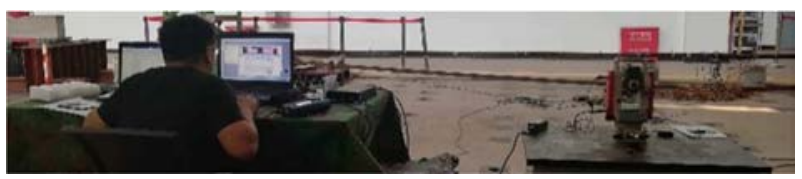

(b) Vibration testing program

Figure 2. Vibration testing program of cable specimen.

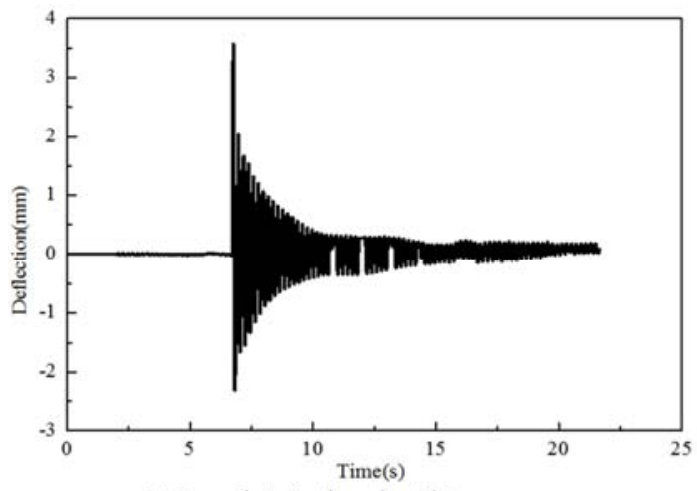

(a) Dynamic deflection time history curve

\section{Experimental Results Discussion}

\subsection{Fundamental Frequency of the Cable}

The case of J4 is as example. Its dynamic deflection time history curves of each target is extracted respectively, and the frequency spectrum analysis is carried out as shown in Figure $3 \sim 8$. The Figure $3 \sim$ figure 8 show that the transformed fundamental frequency of the cable specimen corresponding to the dynamic deflection time history curve of each target is basically the same during loadingcase. Therefore, the effect of measure point position on the fundamental frequency of the cable is little.

Figure 3. The result of dynamic deflection and frequencies spectrum of target of N0. 1.

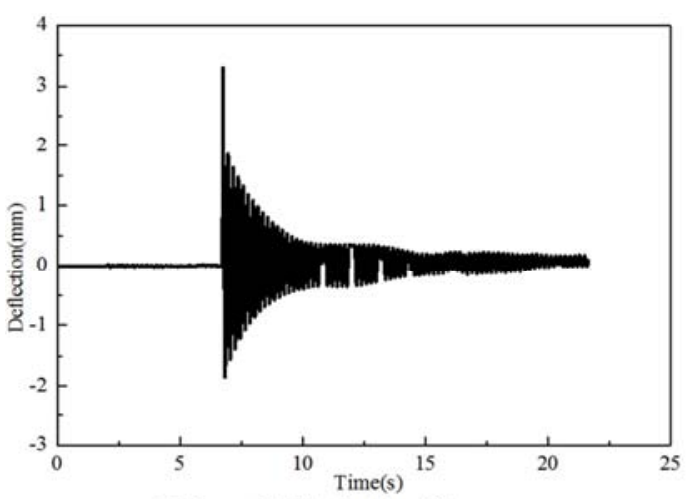

(a) Dynamic deflection time history curve

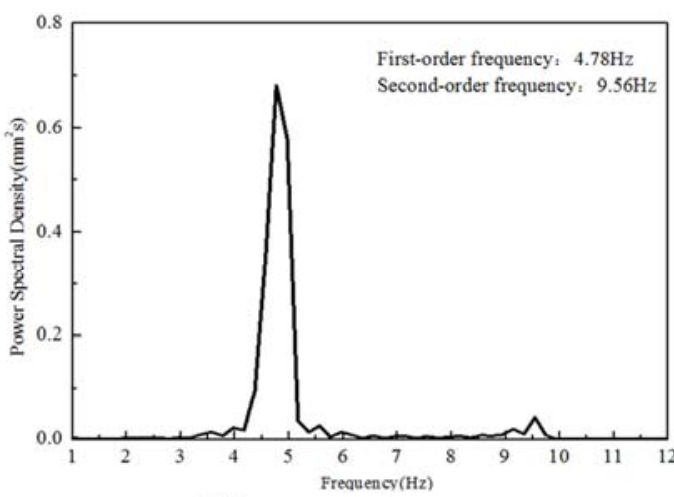

(b) Frequency spectrumcurve

Figure 4. Theresult of dynamic deflection and frequencies spectrum of target of NO. 2.

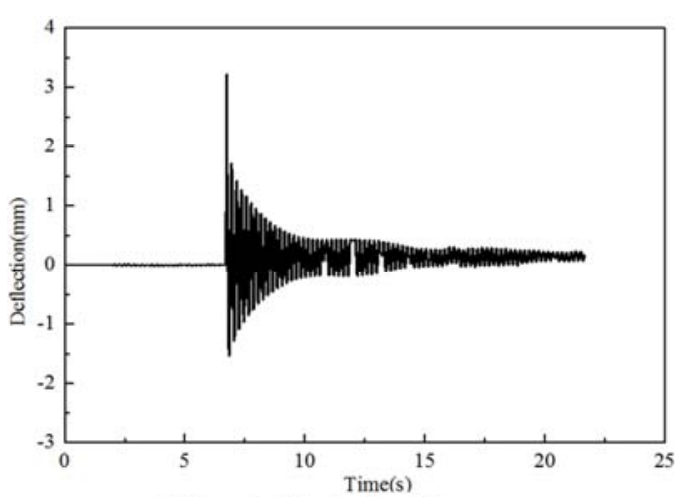

(a) Dynamic deflection time history curve

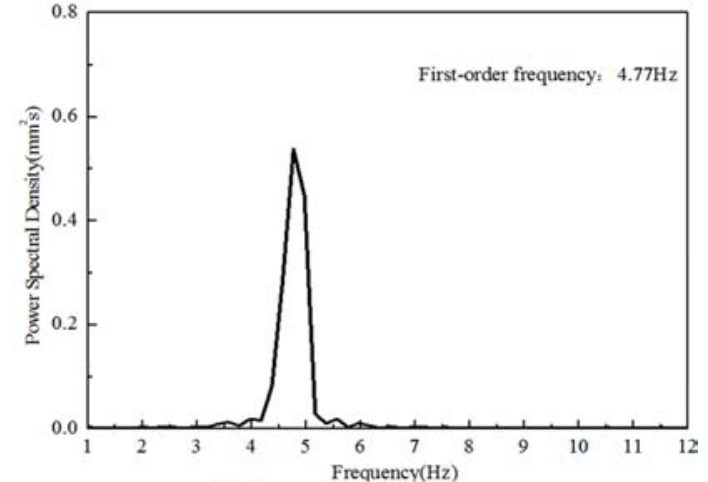

(b) Frequency spectrum curve

Figure 5. The result of dynamic deflection and frequencies spectrum of target of NO. 3. 


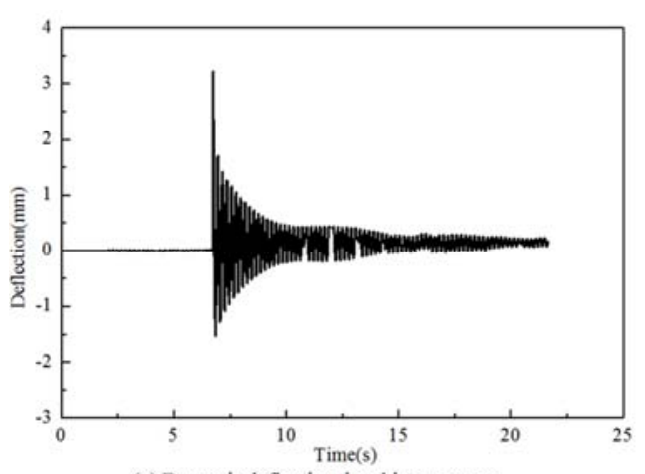

(a) Dynamic deflection time history curve

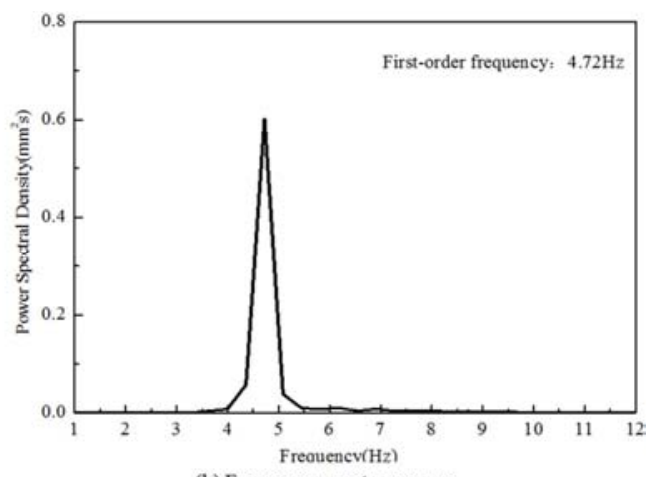

(b) Frequency spectrum curve

Figure 6. The result of dynamic deflection and frequencies spectrum of target of NO. 4.

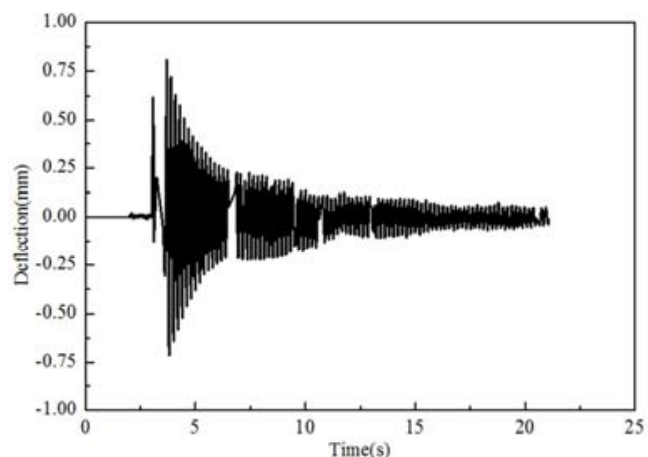

(a) Dynamic deflection time history curve

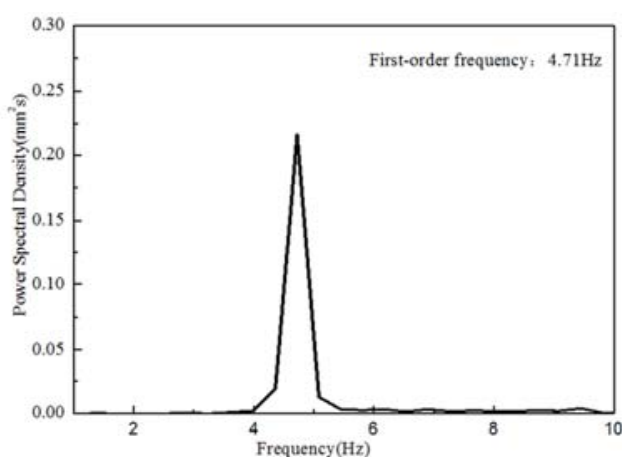

(b) Frequency spectrum curve

Figure 7. The result of dynamic deflection and frequencies spectrum of target of NO. 5 .

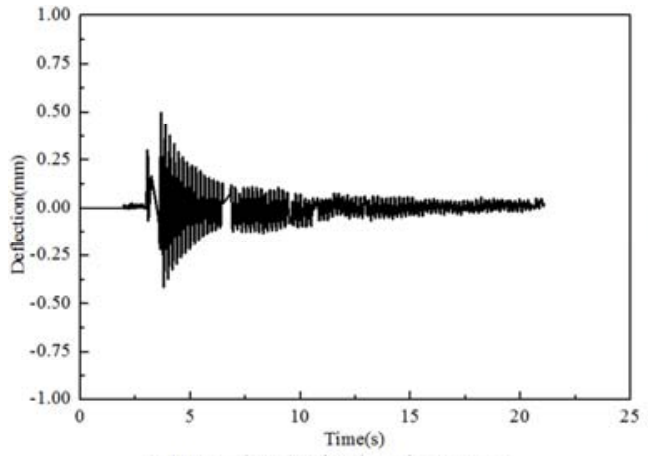

(a) Dynamic deflection time history curve

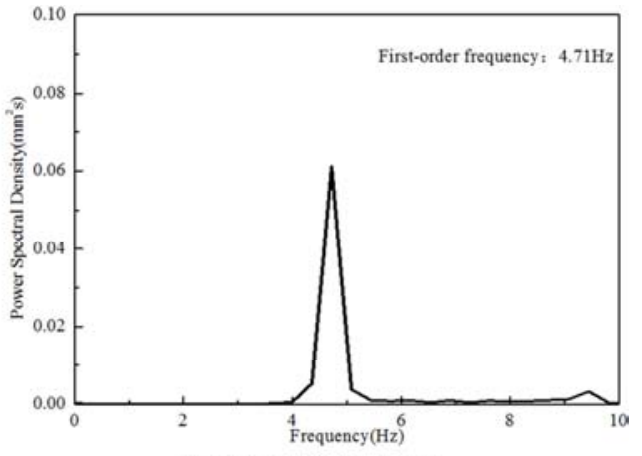

(b) Frequency spectrum curve

Figure 8. The result of dynamic deflection and frequencies spectrum of target of NO. 6.

The fundamental frequency results of the test cable are shown in Table 2. The fundamental frequency variation trend of the cable specimen under loading and unloading is shown in Figure 9. The results in Figure 9 and Table 2 show that the

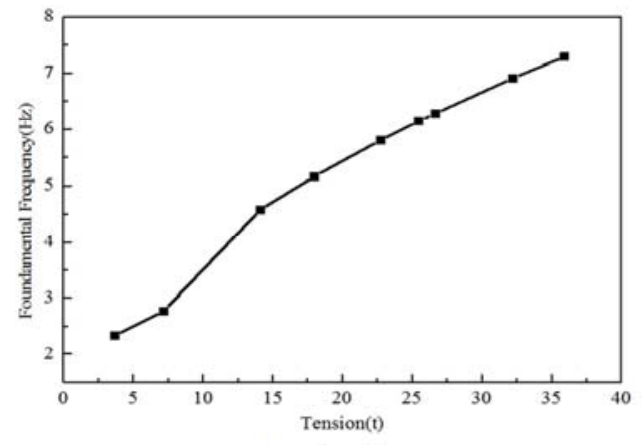

(a) Loading case fundamental frequency increases with the increase of tension under loading case, and it decreases with the decrease of tension under unloading case.

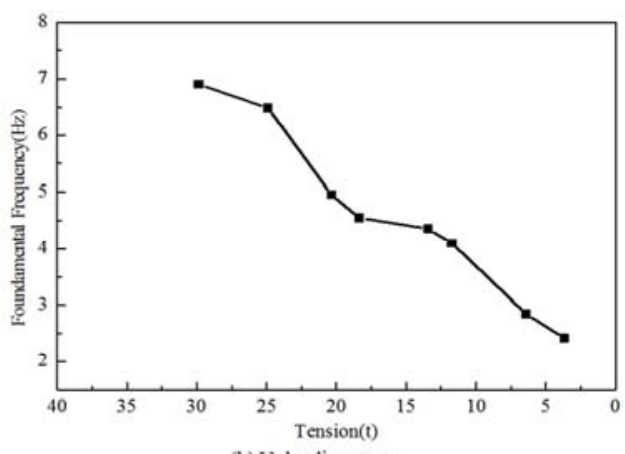

(b) Unloading case

Figure 9. The fundamental frequency change trend of the test cable. 
Table 2. Frequency result of the cable specimen.

\begin{tabular}{|c|c|c|c|c|}
\hline \multirow[t]{2}{*}{ Case number } & \multicolumn{3}{|c|}{$\begin{array}{l}\text { Fundamental frequency } \\
/ \mathrm{Hz}\end{array}$} & \multirow{2}{*}{$\begin{array}{l}\text { Steel strand number } \\
\text { under loading and } \\
\text { unloading }\end{array}$} \\
\hline & $2 \mathrm{t}$ & $4 t$ & $6 \mathrm{t}$ & \\
\hline $\mathrm{J} 1$ & 2.11 & 2.33 & 1 & 1 \\
\hline $\mathrm{J} 2$ & 2.60 & 2.77 & I & 2 \\
\hline $\mathrm{J} 3$ & 3.36 & 4.08 & 4.58 & 3 \\
\hline J4 & 4.66 & 4.78 & 5.16 & 4 \\
\hline loading & 4.30 & 5.69 & 5.80 & 5 \\
\hline J6 & 5.82 & 5.90 & 6.14 & 6 \\
\hline J7 & 5.58 & 5.53 & 6.28 & 7 \\
\hline J8 & 6.71 & 6.86 & 6.91 & 8 \\
\hline J9 & 7.09 & 7.34 & 7.29 & 9 \\
\hline $\mathrm{X} 1$ & 6.91 & & & 9 \\
\hline $\mathrm{X} 2$ & 6.49 & & & 8 \\
\hline $\mathrm{X} 3$ & 4.96 & & & 7 \\
\hline $\mathrm{X} 4$ & 4.55 & & & 6 \\
\hline unloading & 4.36 & & & 5 \\
\hline X6 & 4.10 & & & 4 \\
\hline $\mathrm{X} 7$ & 2.85 & & & 3 \\
\hline $\mathrm{X} 8$ & 2.42 & & & 2 \\
\hline X9 & / & & & 1 \\
\hline
\end{tabular}

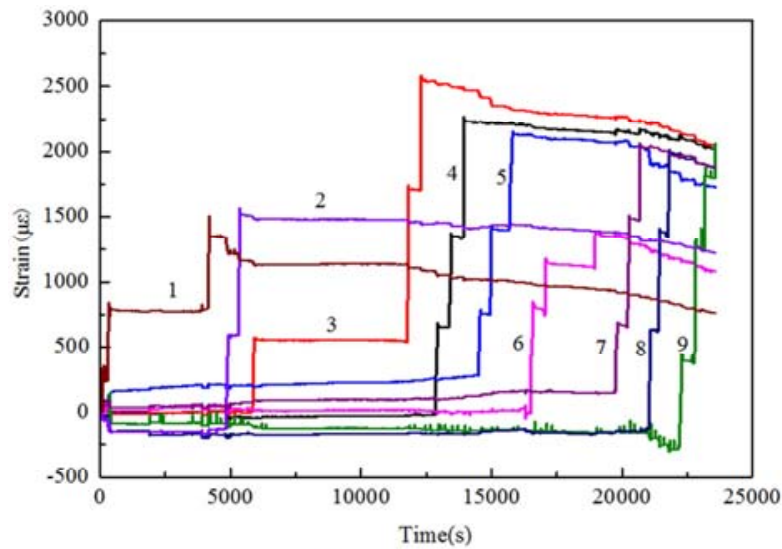

(a) Loading case

\subsection{The Tension Strain of the Test Cable}

The measured strain values of steel strand for loading case are extracted as shown in Table 3. The strain development trend of steel strand corresponding to loading case is shown in Figure 10(a). Table 3 and Figure 10(a) show that the tensile strain of each steel strand increases with the increase of tensile force. The tension of the subsequent steel strand can decrease the tension strain of the stretched steel strand, that is, the tension of the stretched steel strand is reduced.

The tensile strain variation trend of each steel strand for unloading case is shown in Figure 10(b). The measured strain values of steel strands for unloading case are shown in Table 3 . As shown in Figure 10(b) and Table 3, the outward force is applied to anchorage device of each steel strand during unloading, and the tension is unloaded to zero. Before the tension of steel strands is unloaded completely, the tensile strain of unloaded steel strand suddenly increases, however, the tensile strain of other steel strands varies little.

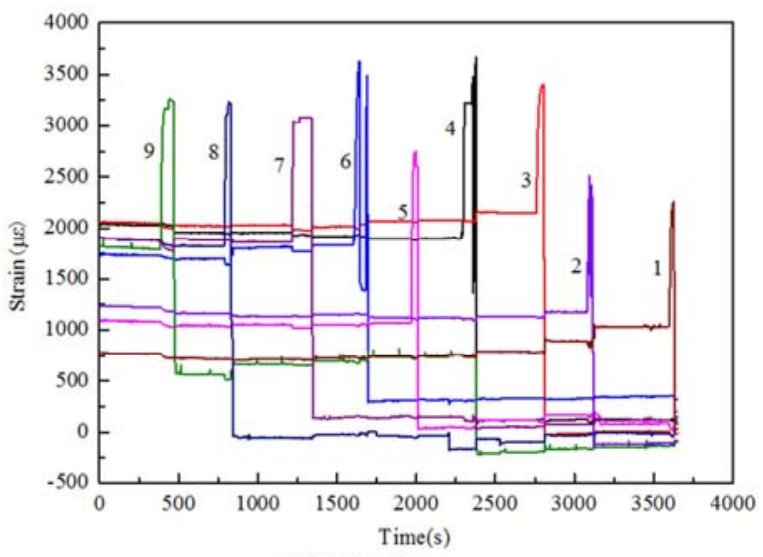

(b) Unloading case

Figure 10. Strain development trend of steel strands.

Table 3. Measured strain value of steel strands $(\mu \varepsilon)$.

\begin{tabular}{|c|c|c|c|c|c|c|c|c|c|c|}
\hline & Steel Strand Number & 1 & 2 & 3 & 4 & 5 & 6 & 7 & 8 & 9 \\
\hline \multirow{9}{*}{$\begin{array}{l}\text { Loading } \\
\text { case }\end{array}$} & 1 & 1349 & 1159 & 1079 & 1029 & 1000 & 1350 & 882 & 828 & 762 \\
\hline & 2 & -123 & 1508 & 1445 & 1426 & 1441 & 1382 & 1331 & 1291 & 1238 \\
\hline & 3 & 0 & 0 & 2541 & 2414 & 2331 & 2255 & 2240 & 2162 & 2057 \\
\hline & 4 & 0 & 0 & 0 & 2227 & 2208 & 2147 & 2152 & 2096 & 2030 \\
\hline & 5 & 218 & 206 & 253 & 266 & 2125 & 2060 & 2031 & 1845 & 1740 \\
\hline & 6 & 0 & 0 & 0 & 0 & 0 & 937 & 1278 & 1185 & 1093 \\
\hline & 7 & 0 & 0 & 110 & 114 & 158 & 158 & 2044 & 1964 & 1898 \\
\hline & 8 & -170 & -166 & -162 & -166 & -135 & -157 & -161 & 1991 & 1894 \\
\hline & 9 & -83 & -119 & -131 & -143 & -135 & -158 & -160 & -280 & 1805 \\
\hline & Steel Strand Number & 9 & 8 & 7 & 6 & 5 & 4 & 3 & 2 & 1 \\
\hline \multirow{10}{*}{$\begin{array}{l}\text { Unloading } \\
\text { case }\end{array}$} & Full tension & 1800 & 1885 & 1885 & 1732 & 1087 & 2021 & 2055 & 1230 & 772 \\
\hline & 9 & 0 & 676 & 701 & 737 & 738 & 755 & 0 & 0 & 0 \\
\hline & 8 & 1822 & 0 & 0 & 0 & 0 & 0 & 0 & 0 & 0 \\
\hline & 7 & 1898 & 1864 & 0 & 0 & 0 & 0 & 0 & 0 & 0 \\
\hline & 6 & 1687 & 1805 & 1832 & 0 & 0 & 0 & 0 & 0 & 0 \\
\hline & 5 & 1033 & 1050 & 1045 & 1068 & 0 & 0 & 0 & 0 & 0 \\
\hline & 4 & 1950 & 1955 & 1919 & 1899 & 1906 & 0 & 0 & 0 & 0 \\
\hline & 3 & 2018 & 2026 & 1998 & 2065 & 2078 & 2150 & 0 & 0 & 0 \\
\hline & 2 & 1179 & 1135 & 1155 & 1139 & 1123 & 1123 & 1174 & 0 & 0 \\
\hline & 1 & 726 & 716 & 726 & 737 & 738 & 791 & 897 & 1038 & 0 \\
\hline
\end{tabular}




\subsection{Cable Tension}

According to the frequency spectrum results, the tension of the cable specimen is calculated by the formula (3) as shown in Table 4, and it is compared with cable tension obtained by measured strain. The compared results of the cable tension is shown in Table 5. As shown in Table 5, the maximum difference between calculated and measured tension is about $17.7 \%$. When the unloaded cable tension is less than $20.6 \%$, the difference between calculated and measured tension is less than $10.0 \%$. It can be seen that the tension and tension loss of the cable can be accurately estimated by using the non-contact dynamic deflection technology.

Table 4. The calculated result of cable tension.

\begin{tabular}{|c|c|c|c|c|c|}
\hline \multirow{2}{*}{ Case Numbe } & & \multicolumn{3}{|c|}{ Tension by steps } & \multirow{2}{*}{ Steel Strand Number } \\
\hline & & First step & Second step & Third step & \\
\hline $\mathrm{J} 1$ & & 3.01 & 3.67 & l & 1 \\
\hline $\mathrm{J} 2$ & & 4.57 & 7.68 & l & 2 \\
\hline $\mathrm{J} 3$ & & 7.63 & 11.25 & 14.12 & 3 \\
\hline $\mathrm{J} 4$ & & 14.68 & 15.45 & 18.00 & 4 \\
\hline J5 & & 12.5 & 21.89 & 22.74 & 5 \\
\hline J6 & & 22.90 & 23.53 & 25.48 & 6 \\
\hline J8 & & 30.44 & 31.81 & 32.23 & 8 \\
\hline J9 & & 33.98 & 36.42 & 35.93 & 9 \\
\hline $\mathrm{X} 1$ & & 32.28 & & & 1 \\
\hline $\mathrm{X} 2$ & & 28.47 & & & 2 \\
\hline X3 & & 21.66 & & & 3 \\
\hline $\mathrm{X} 4$ & & 17.24 & & & 4 \\
\hline X5 & unloading & 15.32 & & & 5 \\
\hline $\mathrm{X} 8$ & & 3.33 & & & 8 \\
\hline X9 & & l & & & 9 \\
\hline
\end{tabular}

Table 5. The Comparison Result of the cable tension.

\begin{tabular}{|c|c|c|c|c|}
\hline \multirow{2}{*}{ Case NO. } & \multirow{2}{*}{ Frequency/Hz } & \multicolumn{2}{|l|}{ Cable Tension /t } & \multirow{2}{*}{$\begin{array}{l}\text { (Calculation value - Measure value)/ } \\
\text { Measure value /(\%) }\end{array}$} \\
\hline & & Measure value & Calculation value & \\
\hline $\mathrm{J} 1$ & 2.33 & 3.19 & 3.67 & $13.08 \%$ \\
\hline $\mathrm{J} 2$ & 3.37 & 7.2 & 7.68 & $6.6 \%$ \\
\hline $\mathrm{J} 3$ & 4.58 & 13.66 & 14.12 & $3.26 \%$ \\
\hline $\mathrm{J} 4$ & 5.16 & 19.33 & 18.00 & $-7.39 \%$ \\
\hline J5 & 5.80 & 23.92 & 22.74 & $-5.19 \%$ \\
\hline J6 & 6.14 & 26.53 & 25.48 & $-4.12 \%$ \\
\hline $\mathrm{J} 7$ & 6.28 & 30.95 & 26.67 & $-16.05 \%$ \\
\hline $\mathrm{J} 8$ & 6.90 & 34.80 & 32.23 & $-7.97 \%$ \\
\hline J9 & 7.29 & 38.62 & 35.93 & $-1.82 \%$ \\
\hline $\mathrm{X} 1$ & 6.91 & 33.61 & 32.28 & $-4.12 \%$ \\
\hline $\mathrm{X} 2$ & 6.49 & 30.65 & 28.47 & $-7.66 \%$ \\
\hline $\mathrm{X} 3$ & 5.66 & 25.60 & 21.66 & $-15.4 \%$ \\
\hline $\mathrm{X} 4$ & 5.05 & 20.87 & 17.24 & $-17.39 \%$ \\
\hline $\mathrm{X} 5$ & 4.76 & 17.97 & 15.32 & $-14.75 \%$ \\
\hline X6 & 4.30 & 13.16 & 12.50 & $-5.02 \%$ \\
\hline$X 7$ & 2.85 & 5.65 & 5.49 & $-2.91 \%$ \\
\hline $\mathrm{X} 8$ & 2.22 & 2.83 & 3.33 & $17.7 \%$ \\
\hline
\end{tabular}

\section{Conclusion}

A cable specimen with length of $12 \mathrm{~m}$ was designed and made, and the steel strand is used in it. The vibration testing for the cable specimen is carried out by applying non-contact dynamic deflection device, and the cable tension is obtained. The frequency of the cable and the strain of steel strands are extracted and compared. The experimental results and conclusions are stated as follows.

(1) The fundamental frequency of the cable specimen corresponding to the dynamic deflection time history curve of each target is basically the same during loading, it shows that the effect of measure target position on the fundamental frequency of the cable is obviously little.

(2) The fundamental frequency increase with the increase of tension under loading case, and it decreases with the decrease of tension under unloading case. In addition, the tension of the subsequent steel strand can decrease the tension strain of the stretched steel strand, that is, the tension of the stretched steel strand is reduced.

(3) The maximum difference between calculated and measured tension of the cable is about $17.7 \%$ during loading case. When the unloaded cable tension is less than $20.6 \%$, the 
difference between calculated and measured tension is less than $10.0 \%$. It can be seen that the tension and tension loss of the cable can be accurately estimated by using the non-contact dynamic deflection technology.

\section{Acknowledgements}

This paper is supported jointly by Basic Science Research Fund-Safety Estimation of the Cable on the Basis of Detection and Monitoring Results (2018), Key Research and Development Project of Guangdong Province (2019B111106001) "Intelligent Safety Monitoring and Emergency Management for Great Sea-Crossing Transportation Cluster Project", and Basic Research Funds Project of Research Institute of Highway Science of Transport Ministry (2020-9015).

\section{References}

[1] Z F. Wang. Study on fiber brag grating sensing theory and key technology for bridges and tunnel engineering safety monitoring [D]. Shandong University, 2014. In Chinese.

[2] J X. Li, X J. Qiang, X W. Lang. Design and implementation of clinometer based on fiber brag grating [J]. Piezoelectric and Acousto-optic, 2019, 41 (01): 53-56. In Chinese.

[3] A S. Kurkov, V I. Karpov, A Y. Laptev et a1. Highly efficient cladding-pumped fibre laser based on an ytterbium-doped optical fibre and a fibre Bragg grating [J]. Quant. Electron. 1999, 29 (6): 516-517.

[4] Z H. Liu, Y Q. Pan, YY. Ge. Damage analysis of reinforced all-lightweight concrete beams based on AE parameters [J]. Concrete, 2018 (10): 52-56+61. In Chinese.

[5] R. Mohammed. An insight into the NDT of steel cables by acoustic emission [C]. Science and Technology: Proceedings of the 14th World Conference on Non-Destructive Testing. New Delhi: Pennsylvania State University, 1996: 201-210.

[6] P O. Paulson. Continuous acoustic monitoring of suspension bridges and cable stays [C]. Structural Materials Technology III. San Antonio: SPIE Society of Photo-Optical Instrumentation Engineers, 1998: 205-213.

[7] D S. Li, J P. Ou. Acoustic emission characteristics and damage evolution model of steel strands in tensile test [J]. Journal of Highway and Transportation Research and Development, 2007, 24 (9): 57-60. In Chinese.

[8] L L. Tian. Research on magnetic optic image nondestructive testing technology for defects of conductive material [D]. Electronic Science and Technology of China, 2018. In Chinese.

[9] R. Christen, A. Bergamini, M. Motavalli. Three-dimensional localization of defects in stay cables using magnetic flux leakage methods [J]. Journal of Nondestructive Evaluation, 2003, 22 (3): 93-101.

[10] G S. Park, E S. Park. Improvement of the sensor system in magnetic flux leakage-type nondestructive testing. IEEE Transactions on Magnetics. 2002, 38 (2): 1277-1280.

[11] W M Yan, X J Xu, Y. Li, et al. Cable force measurement based on vibration frequency method and optimization function $[\mathrm{J}]$. Journal of Highway and Transportation Research and Development, 2015, 32 (11): 61-67. In Chinese.

[12] W F. Wang, Y F. Xu, D Q. Han et al. Techniques for Cable Force Measurement During Construction of Yamen Bridge [J]. Bridge Construction, 2003 (1): 23-26. In Chinese.

[13] W Y. Zhu, H Y. Qin, J Z. Li et al. Monitoring cable force of FAST project based on fiber bragg grating sensor external installed on anchorage zone [J]. Journal of Mechanical Engineering, 2017, 53 (17): 23-30. In Chinese.

[14] J S. Jiang, G W. Tang, H P. Liang. Design of cable tension measurement system based on vibration frequency method $[\mathrm{J}]$. Journal of Chongqing Transportation University (Natural Science), 2015, 34 (5): 25-28. In Chinese. 